\title{
Cognitive individualism and the child as scientist program
}

\author{
Bill Wringe \\ Department of Philosophy, Bilkent University, Ankara, Turkey
}

\section{A R T I C L E I N F O}

\section{Article history:}

Available online 16 August 2011

\section{Keywords:}

Philosophy of developmental psychology

Cognitive individualism

Child as scientist

Gopnik

Meltzoff

Kitcher

\begin{abstract}
A B S T R A C T
In this paper, I examine the charge that Gopnik and Meltzoff's 'Child as Scientist' program, outlined and defended in their 1997 book Words, Thoughts and Theories is vitiated by a form of 'cognitive individualism' about science. Although this charge has often been leveled at Gopnik and Meltzoff's work, it has rarely been developed in any detail.

I suggest that we should distinguish between two forms of cognitive individualism which I refer to as 'ontic' and 'epistemic' cognitive individualism (OCI and ECI respectively). I then argue - contra Ronald Giere - that Gopnik and Meltzoff's commitment to $\mathrm{OCI}$ is relatively unproblematic, since it is an easily detachable part of their view. By contrast, and despite their explicit discussion of the issue, their commitment to $\mathrm{ECI}$ is much more problematic.
\end{abstract}

(c) 2011 Elsevier Ltd. All rights reserved.

When citing this paper, please use the full journal title Studies in History and Philosophy of Biological and Biomedical Sciences

\section{Introduction}

In a number of papers in the 1990s, and in their 1997 book Words, Thoughts and Theories, Alison Gopnik and Andrew Meltzoff defended a view of children's conceptual development known as the 'Child as Scientist' view. ${ }^{1}$ On this view there are important parallels between the ways in which children acquire new concepts and the ways in which scientists develop new theories. $^{2}$

Philosophers of science should be interested in Gopnik and Meltzoff's views for at least three reasons. First, Gopnik and Meltzoff (henceforward GM) claim that if their view is correct, then improvements in our understanding of conceptual change in children will shed light on conceptual change in science. Secondly, Gopnik and Meltzoff's understanding of what scientific theories are (and consequently the content of their claim that children's theories are like scientific theories) relies heavily on their understanding of parts of the philosophy of science literature. ${ }^{3}$ So philosophers of science can contribute directly to the evaluation of GM's core claims. Finally, GM suggest that the Child as Scientist program underpins an argument for scientific realism. ${ }^{4}$ This claim depends on the idea that the sorts of mechanisms which underlie children's conceptual development are likely to issue in true theories. For cognitive mechanisms which lead children to develop false theories of domains which play a central role in their lives would be a massive evolutionary disadvantage. So the cognitive mechanisms which underlie children's conceptual development are likely to be truthconducive. But if so and if the same mechanisms underlie the development of scientific theories, then it appears to follow that scientific theories are the product of truth-conducive mechanisms. This argument is obviously relevant to debates about at least some forms of scientific realism.

E-mail address: wringe@bilkent.edu.tr

1 Gopnik (1996, 1998, 2003), Gopnik \& Meltzoff (1997, 1998), Gopnik, Meltzoff, \& Kuhl (1999).

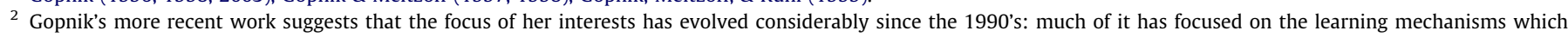

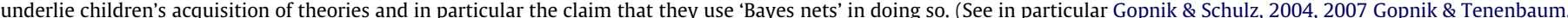

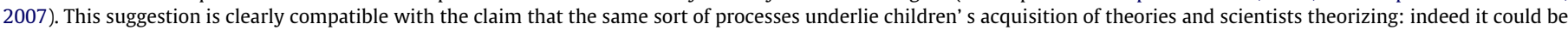
taken to be one way of making that claim more specific.

${ }^{3}$ See Gopnik \& Meltzoff (1997, pp. 32-33).

${ }^{4}$ Gopnik 1996; Gopnik \& Meltzoff (1997, pp. 18-20). 
I shall argue that the second of these reasons for being interested in GM's views undercuts the first and the third. GM's views about the nature of science involve a commitment to a cluster of views which I shall refer to as 'Cognitive Individualism. ${ }^{5}$ This leads them to downplay the cognitive and epistemological significance of distinctive forms of social organization that are characteristic of many forms of scientific enquiry. However, a significant body of recent work in analytic philosophy of science suggests that if we ignore the social dimensions of scientific enquiry we miss something which is distinctive of science, and essential to explaining its success. $^{6}$ This work suggests that there is a serious obstacle to the projects of learning about conceptual change in children by studying conceptual change in science and vice versa. If so, the claims that GM make for the relevance of developmental psychology to philosophy of science cannot stand.

GM's disregard of the social aspects of science has been criticized before. ${ }^{7}$ However, these criticisms have typically failed to specify which aspects of the social nature of science GM have ignored, or why ignoring them is problematic. To criticise GM more effectively we will need to distinguish between what I shall 'ontic cognitive individualism' - a view about what theories are - and 'epistemic cognitive individualism' - a view about what explains the success of science. GM's commitment to ontic cognitive individualism is relatively unproblematic, since it turns out to be inessential to their view. Their commitment to epistemic cognitive individualism is both problematic and essential to their view. ${ }^{8}$

In this paper, I shall draw on work by Philip Kitcher and Miriam Solomon, to argue both that contemporary science involves a form of division of cognitive labour, and that the existence and exact form of this cognitive division of labour play an important role in explaining the epistemic success of science. This second claim is incompatible with the sort of epistemic cognitive individualism which is essential to Gopnik and Meltzoff's view.

Criticisms of GM's commitment to epistemic cognitive individualism need to be developed with care, since, in their 1997 book GM make some concessions to critics of epistemic cognitive individualism and in particular to Kitcher's views. However I shall argue that GM's concessions do not go far enough: they do not appreciate how deep the critique of epistemic cognitive individualism cuts or how far their view would need to be revised in order to accommodate it effectively.

\section{The anti-individualist challenge to the child as scientist program}

To see why it is worth distinguishing between different kinds of cognitive individualism in assessing GM's position, consider the following passage from Miriam Solomon's brief commentary on Gopnik (1996).

'The Scientist as Child is not only incomplete, it is also inaccurate. One important area of inaccuracy is the assessment of the role of 'social factors' (this includes motivational, social, political, economic influences) in scientific decision-making.
Gopnik thinks that 'social factors must have little influence, because, she asserts that children's cognitive processes are similar to scientists while their sociology is different. Even if Gopnik were granted these two assertions ... social factors can still play a crucial role in theory choice. I have argued ... that scientists sometimes form a consensus on the best theory while each scientist involved is making a decision that is strongly and variously affected by 'social factors.' Consensus can be brought about by a variety of mechanisms.'

(Solomon, 1996, p. 549, italics mine)

Call the view that social factors do not play any role at all in theory choice 'Basic Cognitive Individualism.' As Solomon points out, many philosophers of science have argued that $\mathrm{BCI}$ is false. ${ }^{9}$

GM are not committed to BCI. They concede that in at least some scientific fields - such as high-energy particle physics - a social division of epistemic labor plays a crucial role in gathering evidence for scientific theories; and evidence is surely one thing which is relevant to theory choice. ${ }^{10}$ Furthermore, a commitment to $\mathrm{BCI}$ is inconsistent with a central aspect of the Child as Scientist view. On that view, there are important similarities between the cognitive processes of scientists and children. Yet it would be absurd to hold that a claim analogous to $\mathrm{BCI}$ was true of children. That would involve holding that social factors played no role in the cognitive development of children. That is false; GM say it is false; and they cite evidence for its falsity. ${ }^{11}$

Arguably though, in the quoted passage, Solomon is not simply objecting to BCI. She claims, after all, that social factors do not simply play some role in theory choice, but that they play 'a crucial role.' However, she does not spell out here what this crucial role is. So it is difficult to assess the extent to which her criticism undermines GM's position. In particular, it is not clear from what she says here whether the 'crucial role' that social factors play in theory choice can explain what GM say is 'the most important thing about science, namely that it gets things right' (Gopnik \& Meltzoff, 1997, p. 16). GM suggest, by contrast, that 'it is difficult to see how the ... sociological features of science could explain its epistemological potency.' (ibid p16).

\section{Cognitive Individualism - A Brief Taxonomy}

To assess whether GM's commitment to cognitive individualism is problematic, we need to look more carefully at how social factors play a role in scientific cognition. In particular, we need to distinguish between individualist views of what scientific theories are, and individualist theories about what explains the success of science - between ontic and epistemic versions of cognitive individualism.

I shall use the phrase 'ontic cognitive individualism' (OCI for short), to refer to the following pair of claims

OCI (i) Scientific theories are sets of representations

OCI (ii) The representations which constitute scientific theories are in the heads of individual scientists.

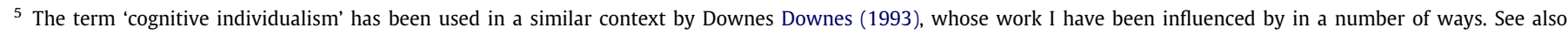
Section 3 below.

${ }^{6}$ Hull (1988), Hankinson Nelson (1990), Longino (2002), Kitcher (1993), Downes (1993), Thagard (2000), Solomon (2001), Goldman (1999, 2004).

7 Solomon (1996), Stich \& Nicholls (1998), Giere (2002).

8 My understanding of the term 'cognitive individualism' has something in common with that of Downes (1993). Downes defines cognitive individualism thus:'cognitive

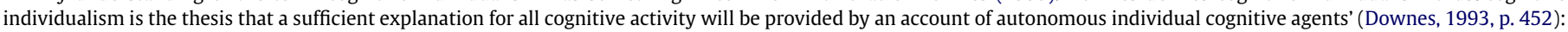

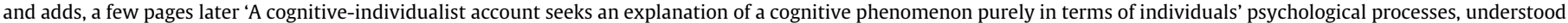
as internal mechanisms' (ibid, p. 454).

${ }^{9}$ See footnote 6 above.

10 Gopnik \& Meltzoff (1997, pp. 24-26).

11 Ibid, pp. 70-71.
} 
$\mathrm{OCI}$ is a view about what scientific theories are. It can be contrasted with the Platonist view that theories are sets of abstract objects such as propositions, or models conceived of set-theoretically; and also with what one might call the 'social materialist ' idea that they are partially constituted by material paraphernalia or apparatus, externally embodied representations, or collective practices involving the competent use of such external material objects. ${ }^{12}$ (However, it is not incompatible with the view that embodied representations, apparati, or practices are causally necessary for the formation of the sorts of sets of representations that constitute scientific theories. $)^{13}$ GM's commitment to $\mathrm{OCI}$ has been criticised by Ron Giere. ${ }^{14}$

OCI can be distinguished from the following claim, which I shall refer to as 'Epistemic Cognitive Individualism, or ECI:

$\mathrm{ECI}$ ) It is possible to give an adequate explanation of the epistemic success of science by considering only the semantic and epistemic relationships between sets of representations which constitute theories and relationships between those theories and those aspects of the world they purport to describe.

This formulation of ECI may initially seem opaque. Here is a brief gloss. ECI is not simply the truistic view that semantic and epistemic relationships between different representations and between those representations and the world they purport to represent are relevant to explaining the success of science. What ECI adds to this is the claim that these are the only factors we need to consider when trying to explain the epistemic success of science. ${ }^{15}$

$\mathrm{ECI}$ is an individualistic view because of what it denies: namely that social relationships between thinkers are relevant to explaining the success of science. It is a form of cognitive individualism because what it is individualistic about is a form of cognition - namely scientific cognition; and it is worth describing as epistemic cognitive individualism because it focuses on questions about how scientific theories are able to constitute knowledge; in other words questions of how it acquires its epistemic status. ${ }^{16,17}$

ECI entails a commitment to denying that things other than semantic or epistemic relationships between representations or between those representations and the world are relevant to explaining the epistemic success of science, and in particular, to denying that features of the social and institutional organization of science, such as social and institutional relationships between individuals who generate or possess scientific theories are relevant to explaining the epistemic success of science. Critics of ECI include both Philip Kitcher and Miriam Solomon. ${ }^{18}$
OCI and ECI are distinct and mutually compatible views which are not (in the absence of further assumptions) mutually entailing. They do not exhaust the range of views which might fall under the label 'Cognitive Individualism'. For example, they are both distinct from what I described in section 1 as 'Basic Cognitive Individualism': one could deny $\mathrm{BCI}$ while accepting one or both of $\mathrm{ECI}$ and $\mathrm{OCI}$.

(One might suppose he distinction that I am making between $\mathrm{ECI}$ and $\mathrm{OCI}$ to have been anticipated - in a slightly different context - by Stephen Downes. ${ }^{19}$ Towards the end of a critique of (what he calls) cognitive individualism, he distinguishes the point that cognitive individualist accounts of science are descriptively inadequate from the claim that they provide us with an inadequate basis for making normative judgments about science. This distinction may seem to parallel the distinction I make between OCI and ECI. However, it is not clear whether Downes thinks of OCI and ECI as being distinct theses; and his view of the relationship between these issues seems different from mine. He argues that since OCI presents us with a descriptively inadequate view of science, the sorts of normative views that are put forward by proponents of $\mathrm{OCI}$ are likely to be suspect. By contrast, I suggest that even if Gopnik and Meltzoff were to give up $\mathrm{OCI}$, their commitment to $\mathrm{ECI}$ would still be problematic. ${ }^{20}$ )

\section{The 'child as scientist' view: some ambiguities}

Before we can attempt to assess the nature and depth of GM's commitment to one or another version of Cognitive Individualism, we need to look more closely at their views. We need to know what exactly they are comparing children's theories to; the precise relationship which they take to hold between children's theories and scientific theories; and which aspects of children's cognitive structures they take to be theory-like. ${ }^{21}$

\subsection{What are GM comparing to what?} View:

Here is one prominent formulation of the Child as Scientist

'Children's conceptual structures, like scientists', are theories ... their conceptual development is theory-formation and change and their semantic development is theory dependent.'

(Gopnik \& Meltzoff, 1997, p. 13) - emphasis mine

Steven Downes and Michael Bishop have noted that this quotation can be understood in a number of ways. ${ }^{22}$ First, GM might be

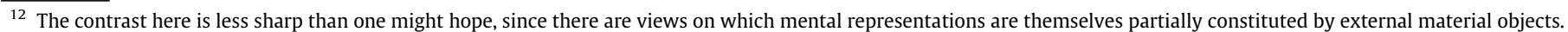

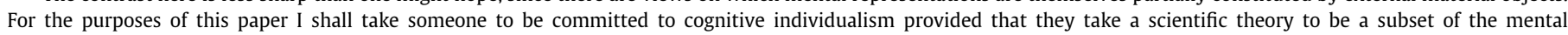
representations of one individual, no matter what further view they take of the nature of mental representations.

13 Giere (2002).

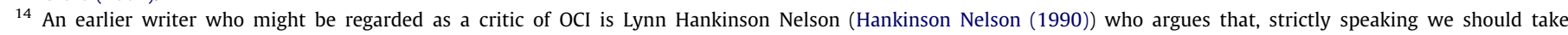

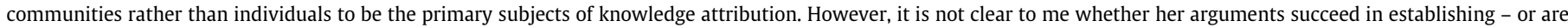

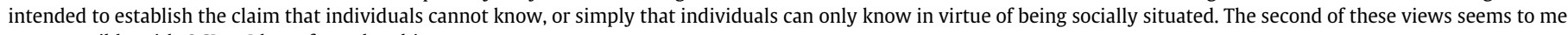
to compatible with $\mathrm{OCI}$ as I have formulated it.

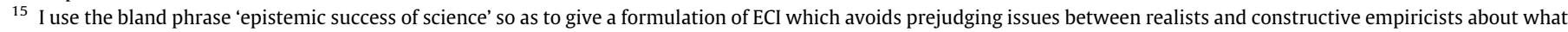
constitues scientific success. See van Fraassen, 1980, 2002.

16 See Section 4 (pp13ff below) for evidence of Gopnik and Meltzoff's commitment to ECI.

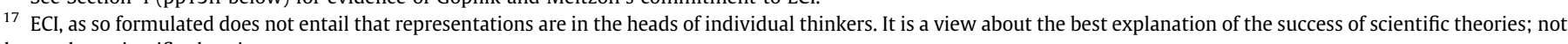
about what scientific theories are.

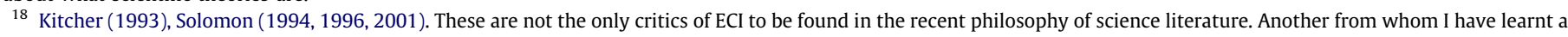

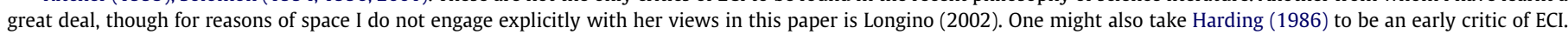

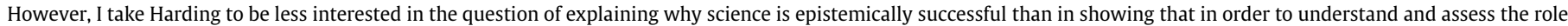
of science in society we need to be fully aware of the ways in which the production and dissemination of scientific knowledge depends on a division of cognitive labour.

19 Downes (1993).

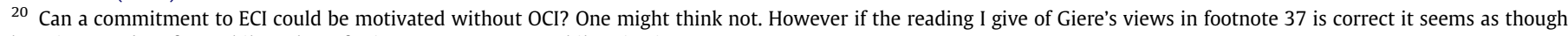
there is precedent for a philosopher of science to accept ECI while rejecting OCI.

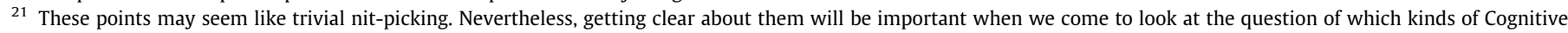
Individualism Gopnik and Meltzoff are committed to, and to assess how they might respond to objections on this score, something which is essential to my purposes here.

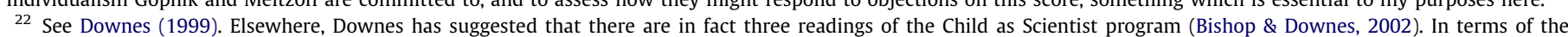

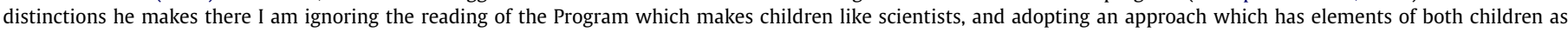
super-scientists and children as social institutions.
} 
interested in a comparison between the ways in which children's concepts change and the ways in which individual scientists acquire the concepts which belong to existing scientific theories. Alternatively, they might be concerned with comparing the ways in which children acquire new concepts and the ways in which the scientific community as a whole comes to believe new theories, containing new concepts.

Bishop and Downes argue that philosophers should be most interested in the second reading of GM's position. I agree. Consider the argument for scientific realism mentioned in section 1. This purported to show that the fact that children's theorizing and scientific theorizing are subserved by the same mechanisms gives us reason to think that scientific theorizing will tend to yield true theories. As Bishop and Downes point out, a defender of scientific realism needs to show that science as a whole has a tendency to produce true theories, not that individual scientists do. For, viewed at the level of the productions of individual scientists, what our theory-producing mechanisms come up with is false at least as often as it is true. It is only when we consider science as a whole that what we have to defend is a surprising record of success. ${ }^{23}$

I shall be arguing against this version of the Child as Scientist view. If ECI is false - in other words, if the social organization of science plays an important role in explaining its epistemic success, then it is implausible that we can learn a great deal about either the nature of science or the workings of the child's mind by comparing them in the way that GM suggest. In other words, we should see science as a whole as producing epistemic outputs which are successful for reasons which are interestingly different from the reasons for which individual children's epistemic outputs are (epistemically) successful. If ECI is false, then the epistemic success of science depends, in non-trivial ways, on the organization of multiple cognitive agents.

By contrast, children are individual cognitive agents. Whatever their epistemic success depends on, it is not the way they are organized. This is not to say that the learning of children does not take place in any kind of social setting - that claim is flatly implausible, Nor is it to say that the social setting plays no role in explaining children's learning. It is simply to point out that there is no reason to suppose that there is anything within the mind of individual children which plays an analogous role to that of the social structure of science, taken as a whole. ${ }^{24}$

There is good textual evidence that GM intend their view to be understood in the way I have outlined. Their attempts to mine theories about conceptual change within a scientific domain as a whole - such as the work of Kuhn and Lakatos - for a plausible account of what children's theories are seem hard to account for on any other reading. ${ }^{25}$

Nevertheless, one might take GM to be arguing for a different view - namely that young children and scientists rely on similar mechanisms for generating and assessing theories. ${ }^{26}$ The arguments which I shall be putting forward tell against this view too. If ECI is false, then the epistemic success of science depends on the interaction of a range of psychological mechanisms and forms of social organization. If young children enjoy a comparable measure of epistemic success, it is presumably produced by an interaction between whatever cognitive mechanisms are present in young children and what is - presumably - a rather different form of social organization. It may be reasonable to infer like causes from like effects, it is less reasonable to infer that when two like effects are produced by unknown causes interacting with discernibly different further causes that the unknown causes are the same - unless one thinks that the contribution of the unlike causes is negligible.

\subsection{What relationship do GM think holds between children's theories and scientific theories?}

In characterising the 'Child as Scientist' view, GM are unclear about the kind of relationship they take to hold between scientific theories and children's theories. ${ }^{27}$ Sometimes, as in the quotation given in section $3 a$ ) they seem to be saying that the two are the same. Sometimes they say that they are similar (or perhaps identical):

'The central idea ... is that processes of cognitive development in children are similar to, perhaps even identical with; the processes of cognitive development in scientists.'

(Gopnik \& Meltzoff, 1997, p. 3 , emphasis mine)

Sometimes they say that there is an analogy

'Very young children just beginning to talk are engaged in profound restructurings of several domains of their knowledge. These restructurings are analogous to theory changes.'

(ibid p7 emphasis mine)

I shall argue below that when GM formulate their view in the first or second of these ways, they commit themselves to OCI. When they formulate it in the third way they do not. GM will be able, then, to meet criticisms of their view which depend on the untenability of $\mathrm{OCI}$ by retreating from a formulation of the first or second sort to one of the third sort - that is by retreating from a formulation couched in terms of identity or similarity to one couched in terms of analogy. ${ }^{28}$

\subsection{What do GM take theories to be?}

\section{GM characterize theories as follows:}

'A person's theory is a system that assigns representations to inputs just as one's perceptual system assigns representations to visual input or one's syntactic system assigns representations to phonological input. The representations ... are ... distinctive in many ways... We can capture these distinctive structural features by talking about the specific abstract, coherent, causal, ontologically committed, counterfactual supporting entities and laws of the theory ... The representations are also operated on by rules that lead to new representations ... There are also distinctive functional relations between theoretical representations and the input to them; theories predict interpret and explain data'

(Gopnik \& Meltzoff, 1997, p. 43)

\footnotetext{
${ }^{23}$ Bishop and Downes (2002).

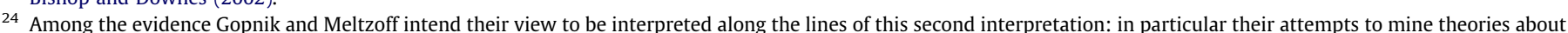
conceptual change within a scientific domain as a whole - such as the work of Kuhn and Lakatos - for a plausible account of what children's theories are.

${ }^{25}$ Gopnik \& Meltzoff, 1997, p. 25.

26 This is also seems suggested by some of Gopnik's more recent work

27 Glennan (2005) both notes and plays down the significance of this ambiguity.

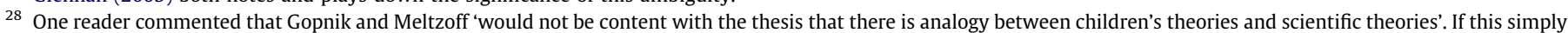

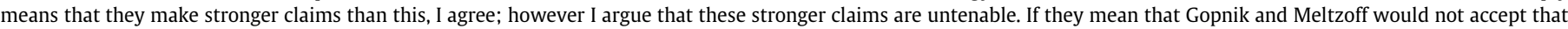
there are such analogies, I am at a loss to understand how they intend the passage I have quoted.
} 
They go on to say

'If we discovered that children's representational system (sic) had the features we have been describing (sc - those mentioned in the paragraph I have just cited) we would ... be licensed in saying that children had theories.'

GM's identification of theories with representation-forming systems, and the analogy which they draw with the visual system is puzzling. It is natural to think of a theory as something which consists of a set of representations, rather than a system that produces such representations. Furthermore the (admittedly enthymematic) argument that GM put forward for holding that children have theories seems to involve showing that some of the sets of representations have the same features as those sets of representations that we normally characterize as scientific theories. But if this argument gives us reason to believe anything, it is that certain sets of representations in children's minds are theories, not that the systems which form those representations are.

(This distinction may appear to be trivial, ${ }^{29}$ especially if the fact that the word 'system' means something rather different in the two phrases is overlooked. In the phrase 'system of representations', 'system' means 'an organized collection' while in the phrase 'representation forming system' it means a mechanism or set of mechanisms for producing representations. Consequently, what it makes sense to say about 'systems of representations' - and what might conceivably be true of them is rather different from what it might make sense to say - and what might be true of representation-forming systems.)

Since the claim that theories are representation-forming systems, rather than systems of representations, does not surface again, I shall take GM not to be committed to it but instead to the more plausible view that, for which they have in fact argued, that theories are systems of representations, rather than representation-forming systems. ${ }^{30}$

\section{GM's Commitment to OCI and ECI}

In section 3c) I suggested that on a charitable reading of their argument for the claim that young children have theories, GM's argument involved an appeal to the idea that theories are sets of representations in individuals' heads. If so, it turns on a commitment to $\mathrm{OCI}^{31}$

This is also true if we take GM only to be claiming that the mechanisms involved in belief change in children are the same as those involved in scientific theory change. The mechanisms which explain cognitive change in children are certainly mechanisms which operate on sets of representations in the minds of individuals. If the same mechanisms are working when scientific theories change, then what they are working on must also be sets of representations in the minds of individuals.
GM's commitment to ECI comes out when they write:

'A cognitive view of science ... might provide at least a partial explanation of the most important thing about science, namely that it gets things right. In contrast it is difficult to see how the (phenomenological and) sociological features of science could explain its epistemological potency.' mine)

(Gopnik \& Meltzoff, 1997, p. 16 - italics and brackets

However, GM's commitment to $\mathrm{ECI}$ is qualified in one important respect. For they concede that the social organization of science may be relevant to explaining something which is relevant to its epistemic success. It can explain how scientists are able to form true beliefs in situations where it is hard to find evidence in favor of a particular view. As they put it:

Paucity of evidence leads to the division of labor and to many of the ... institutions characteristic of science... To find evidence of a Higgs boson, you need, quite literally an Act of Congress. (p24)

Nevertheless, they insist that while the division of labor may play a significant role in collecting evidence for scientific theories, it plays no role in explaining why the sorts of procedures which are involved in assessing scientific theories are particularly successful in providing us with true theories.

'It's easy to see how the division of labor could result from the need for various forms of evidence... What is extremely hard to see is how ... hierarchy could lead to truth, or how the division of labor could lead to theory formation and confirmation'

Gopnik \& Meltzoff, 1997, p. $24^{32}$

One might think that GM are not really committing themselves to anything like ECI here, and are instead claiming explanations of the success of science will need to involve reference both to representational processes in the heads of scientists, and to institutional factors. ${ }^{33}$ However it is hard to see how GM's words can bear this reading. Admittedly GM say that a cognitive view of science provides us with a 'partial explanation' of 'why science gets things right' and not that it gives a complete explanation. Taken on its own, this claim would of course be consistent with the view that a complete explanation would involve both cognitive, and social factors. However, GM do not continue by claiming that institutional factors can also provide us with a partial explanation of how science gets things right. Nor do they simply say, as someone who thought that GM were not committed to ECI might hope, that it is difficult to see how these features can lead to truth or confirmation on their own. They say that it is difficult to see how they could do so, period. ${ }^{34}$

Both of the critics of ECI whose work I will be examining in what follows hold that scientific division of labor plays an important role in explaining how science arrives at truth. So, it seems

\footnotetext{
29 It seemed so to one anonymous reader.

30 I thank Josh Cowley for pressing me on this.

31 In Section 5 below I shall argue that this commitment is one they could easily avoid. But this does not show that they do not have the commitment

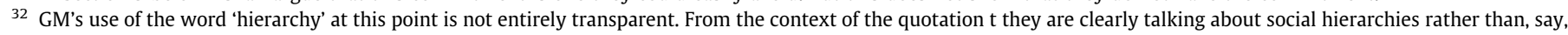

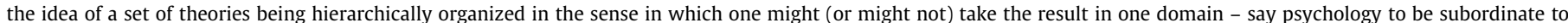

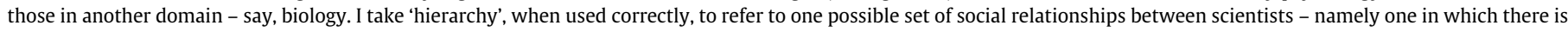

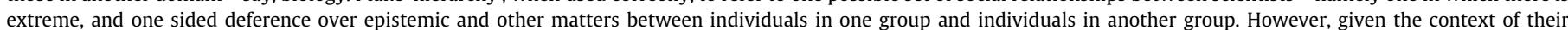

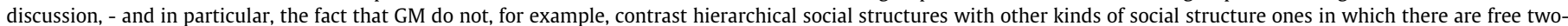

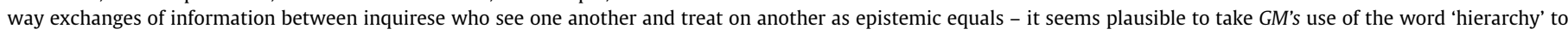

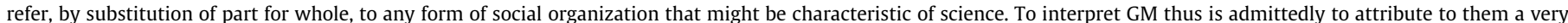

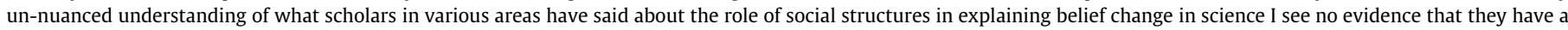
more nuanced view.

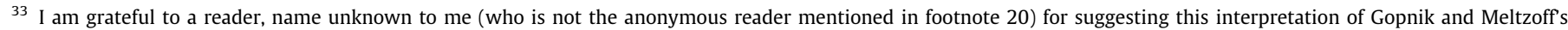
position.

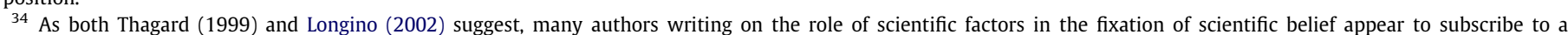

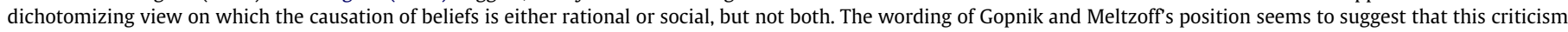
applies here.
} 
reasonable to object that in arguing for their views GM have failed to engage adequately with significant critics of their position. Moreover, if GM's formulations can be read as saying that we need to appeal to both representational and institutional factors in order to explain the success of science, then presumably their view could equally well be formulated as follows:

'An institutional view of science ... might provide at least a partial explanation of the most important thing about science, namely that it gets things right. In contrast it is difficult to see how the representational features of science could explain its epistemological potency.'

I suspect that GM would regard this as a travesty of their view. I think they would be right to do so. But on the interpretation of their view that I am considering (and rejecting) they would have few grounds for objecting to this formulation.

GM do, admittedly, point out that various features of social life contribute to young children's capacity to develop cognitively: These include leisure, lack of other demands on their time and, most importantly 'a community of adults who are designed to act in ways which further the children's cognitive progress' and which 'has an interest in passing on information which is relevant to the child.' ${ }^{35}$ However, these observations provide no reason for qualifying GM's commitment to ECI. ECI is a view about what explains the epistemic success of scientists. But these points are ways in which GM take the social setting of young children to differ from (and be epistemically superior to) that of scientists. So they cannot be taken as evidence of GM's holding that the social setting of scientists contributes to their epistemic success.

Significantly, GM's commitment to ECI does not seem to depend on their commitment to OCI. The points they make which suggest they accept ECI seem to be independent of any claims about what scientific theories are. For example, they are compatible with the view that scientific theories are abstract entities such as sets of sentences; or sets of models - in either Giere's sense on which a model is a kind of abstract entity; or in the technical sense of model taken from model theory. ${ }^{36}$

Furthermore, since ECI is a view about the nature of scientific theories, and the arguments in favour of it depend on GM's views about what could and what could not plausibly explain progressive scientific change, GM's commitment to it is independent of the question of whether they take children's theories to be identical to, similar to, or merely analogous to scientific theories. ${ }^{37}$

\section{Giere's Critique of Ontic Cognitive Individualism}

Ronald Giere has recently argued that an adequate account of scientific knowledge should avoid a commitment to OCI because scientific knowledge involves 'distributed cognition'. ${ }^{38}$ Distributed cognition involves the co-operation of groups of agents interacting with scientific apparatus in such a way that it becomes appropriate to regard the locus of the representational system which constitutes a scientific theory as extending beyond the skin of a single knowing subject. Giere is here denying $\mathrm{OCI}$ ii while accepting $\mathrm{OCI} \mathrm{i}^{39}$ By contrast, GM are committed to both components of OCI. If Giere is correct, there seems to be trouble for GM.

Perhaps problematically, Giere seems to be committed either to the existence of 'group minds' or to the possibility of there being representations without representing subjects. Giere opts decisively for the second horn of this dilemma, suggesting that although scientific theories are representations, they are not internal mental representations. ${ }^{40}$ Rather, they are representations in the mundane and non-mentalistic sense that diagrams on paper, scale models, explicit written mathematical descriptions of phenomena under consideration and the like are representations. ${ }^{41}$

Giere cites in support of his rejection of OCI the highly plausible claim that it is characteristic of many contemporary scientific theories that no particular individual need know everything that is a part of the theory. ${ }^{42}$ However it is unclear whether this claim supports Giere's position. For it seems to be compatible with a wide range of views about what theories are, including the traditional 'syntactic' view, in which scientific theories are regarded as sets of sentences in a formalized language, (where sets of sentences are regarded as abstract entities) and a version of the semantic view, which equates theories with sets of models, where models are regarded as set-theoretical entities. ${ }^{43}$

However, this point does not help GM, who are committed to scientific theories' being sets of representations rather than abstract entities. Someone who thinks that scientific theories are internal representations might try to accommodate Giere's point

\footnotetext{
35 Gopnik \& Meltzoff (1997, p. 25).

36 Giere (1988).

37 See footnote 23 for further discussion of Giere (1988).

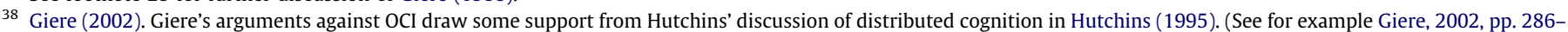

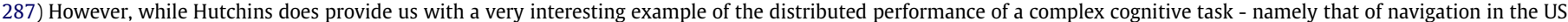

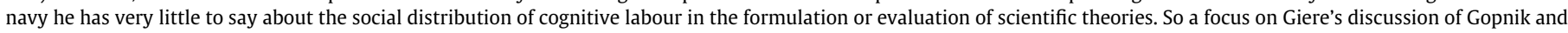
Meltzoff seems more pertinent to my immediate purposes than a detailed discussion of Hutchins' views.

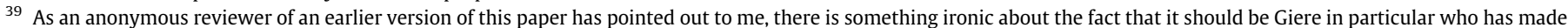

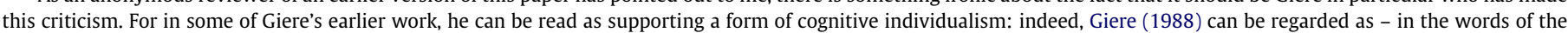

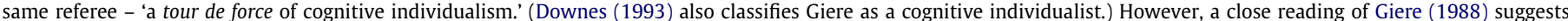

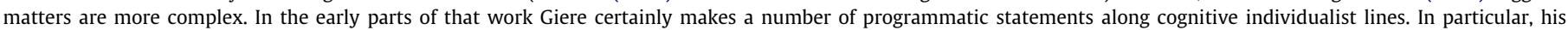

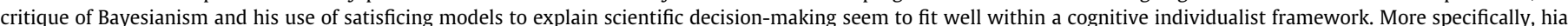

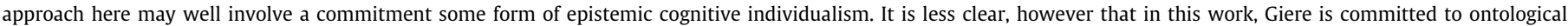

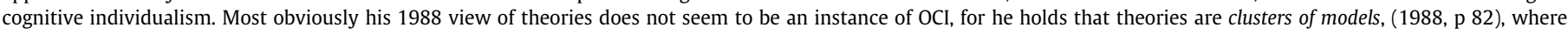

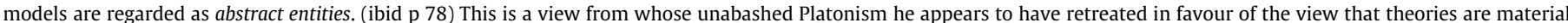

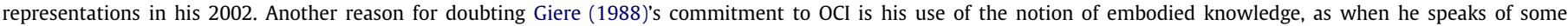

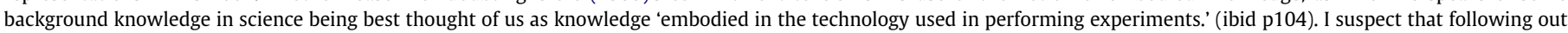

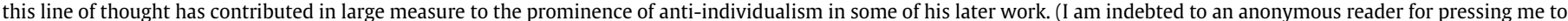
think about the relationship between Giere's earlier and later work).

40 Giere (2002)

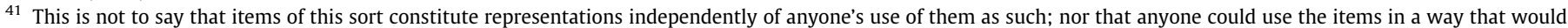

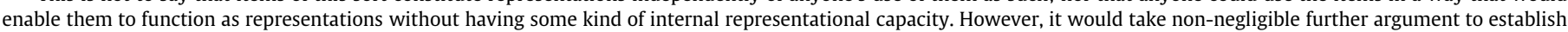
that we should take these use-enabling representations to be scientific theories - or indeed theories of any sort.

42 Giere backs up his claim by reference to case studies in Knorr-Cetina (1999).

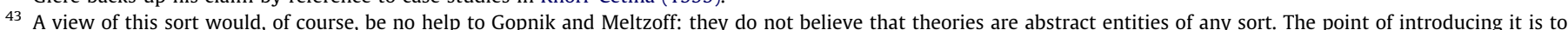

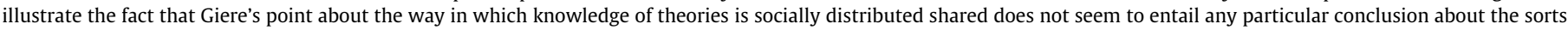
of things theories are. A fortiori, it does not entail that they are not mental representations.
} 
by suggesting that scientific theories are in some way constituted out of representations in the heads of groups of scientists. However a view of this sort would not help GM much either, since it still requires a denial of $\mathrm{OCI}$ ii. In saying that scientific theories were constituted out of representations in the heads of several individuals, one would be conceding an important difference between them and the sorts of things which GM think developmental psychologists should be studying. ${ }^{44}$ For those seem to be, almost by definition, sets of representations within the head of individuals.

Alternatively or additionally, one might suggest that Giere ought to allow for a distinction between two different sorts of things that might be called scientific theories. In other words, one might want to distinguish between the complete theory of any given area - which, as Giere suggests, might not be representable by any one individual, and different individual's 'takes' on or understandings of the theory. As Staley points out, different scientists working in a highly collaborative area may disagree over the significance of a particular experimental result. ${ }^{45}$ Distinguishing between 'personal' and 'complete' theories in the way suggested here helps to explain such phenomena.

However, although Giere might concede that distributed cognition requires some sort of representational resources at the individual level, it is not obvious that, or why, he need concede that these representations are theory-like. They may, for example, involve things that are better regarded as the representational underpinnings of practical abilities to use the theory, rather than as themselves being theories.

However, there is a way out for GM. In section $3 b$, I pointed out that GM wavered in their statements of the relationship between children's theories and scientific theories between claims of identity, similarity, and analogy. As far as Giere's critique of the Child as Scientist program is concerned, it matters which of these formulations we adopt. The claim that scientific theories are the very same sorts of thing as children's theories seems incompatible with a recognition of the distributed nature of scientific theories. By contrast, claims about similarities or analogies between them are not undermined by points of this sort.

Advocates of the Child as Scientist program can, then, respond to Giere's critique by retreating from the claim that scientific theories and children's theories are the same kinds of thing to the claim that they develop in analogous ways. After all two things of different sorts surely can develop in analogous ways. ${ }^{46}$

One might object that claims about the existence of analogies between the ways in which scientific theories develop and the ways in which children's understanding of the world develop are unhelpfully vague. A defender of the Child as Scientist view needs to give a specification of the ways in which these two processes are analogous. Nevertheless GM's discussions of the ways in which particular examples of children's theories develop do precisely this. One might also object that retreating from a version of the Child as Scientist program formulated in terms of identity to one formulated in terms of analogy might be seen as an epistemically retrograde step since it involves abandoning a claim with more content in favor of one with less. However, since GM waver between formulations of the Child as Scientist Program which speak of identity and those which speak of analogy, we might reply that the suggestion that they should abandon the first in favour of the second amounts to a suggestion which increases rather than decreases the contentfulness of their view.

A further objection is that understanding the Child as Scientist Program in the way I have suggested is incompatible with a key claim of GM's - namely, that the mechanisms which underpin theory change in children are the same mechanisms as those which underpin theory change in mature scientists. ${ }^{47}$ To this, I have three comments. First, it is not immediately obvious that the suggestion that these two views are incompatible is true. There is no a priori reason why the same mechanisms should not be involved in the development of two different, but analogously structured kinds of thing. Secondly, even if the suggestion is correct, there is a natural response, namely to suggest that someone who thinks that children's theories are analogous to scientific theories might consider the possibility that the mechanisms which underlies the changes are, while not identical, also analogous. Indeed, when GM write that

'These restructurings (ie, the ones undergone by young children just learning languages - current author) are analogous to theory changes'

it is natural to think that this claim, if true, would at best support a claim that the mechanisms involved in these restructurings were analogous. Thirdly, at the beginning of this paper, I specified three reasons why the Child as Scientist program might be of interest to philosophers of science. Only one of those reasons depended on the idea that the mechanisms involved in theory change in scientists and in children are exactly the same. So whatever GM's own view of the matter I claim that the Child as Scientist program should be of interest even if the claim about identity of mechanisms cannot be sustained.

\section{ECI and the child as scientist program}

\subsection{Why ECI matters}

GM's commitment to ECI is much harder to excise than their commitment to OCI. On their view, part of the appeal of the idea that there is an analogy between the development of science and the development of children's theories about the world is that children's understanding of the world appears to resemble our more sophisticated scientific understanding because both involve examples of progressive convergence on an accurate portrayal of the world via processes which include episodes of revolutionary change. ${ }^{48}$ An obvious corollary is that if we want to exploit the analogy to help us see how children's understanding of the world develops then we will need to draw on our understanding of what it is about science that accounts for its having those features. In other words we will want to appeal to features of science which make it epistemologically special. If children's ways of understanding the world can be shown to lack these features, then this counts heavily against the Child as Scientist program.

In this section I shall argue that contemporary science involves a form of division of cognitive labor, and that this division of cognitive labor plays an important role in explaining the epistemic success of science. If so, then $\mathrm{ECI}$ is false.

Many social factors other than the division of cognitive labour affect the outcome of scientific decisions. These include peer

\footnotetext{
$\overline{44}$ This might seem obvious. However, developmental psychologists in the Vygotskyan tradition, such as Rogoff \& Toma (1997) and Gauvain (1998, 2001).might disagree.

45 Staley (2005).

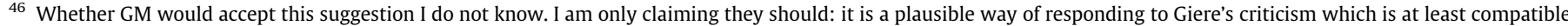

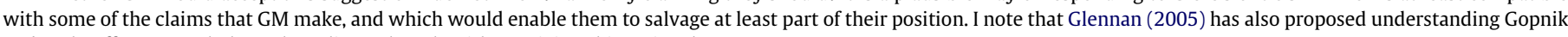
and Meltzoff's proposal along these lines, though without giving this rationale.

47 I am grateful to the anonymous reader cited in footnote 20 for pressing this objection.

48 Gopnik \& Meltzoff (1997, pp. 39,42).
} 
pressure, socially communicated extra-scientific values, ideological commitments on the part of scientists and so on. ${ }^{49}$ However in order to refute ECI it is not enough to establish that social processes play some role in explaining why scientific beliefs change. We must also show that these features play an important role in explaining the epistemic success of science. ${ }^{50}$ The arguments that I shall examine support this claim. It is much harder to establish that the factors mentioned at the beginning of this paragraph play a positive epistemic role than that the division of cognitive labour does. ${ }^{51}$

The arguments I consider will not simply be aimed at showing that the existence of a form of division of cognitive labor in science plays a role in explaining the success of science. They will also support the claim that the particular form that this division of labor takes plays a role in explaining this success. This will help to defuse a certain kind of response to attacks on ECI which involves conceding that certain socially mediated processes are important in mature science; and that such processes do not have a similar input into the content of children's theorizing; but then suggesting that children's theorizing might receive an analogous kind of input from some other source.

Suppose, for example, that one could show that extra-scientific values played a role in making science epistemically successful. A defender of the child as scientist program might suggest that extra-scientific values communicated to children by their care-givers could play an analogous role in the scientific theorizing of children. If the argument being put forward by critics of ECI simply showed that science involved some kind of division of cognitive labor, a similar defense might be mounted: perhaps whatever it is that is important about the existence of a division of cognitive labor in mature science is supplied from somewhere else in children's theorizing. I shall argue, though, than when we look at the details of the positions which Kitcher and Solomon put forward, responses of this sort are quite implausible. It is hard to see how the valuebased argument, or a possible argument based on the role of peer-pressure in scientific decision-making could be developed in a way that made this sort of response in question as implausible.

\subsection{ECI rejected (I): Kitcher}

In their 1997 book, GM respond to suggestions that their position is weakened by their commitment to some forms of cognitive individualism via a discussion of Kitcher (1993). ${ }^{52}$ They argue that the existence of a division of cognitive labor in science is not itself enough to undermine the Child as Scientist Program, suggesting that this division of labor might arise from the fact that the sorts of problem with which these scientists are concerned are ones that are either particularly difficult, and so require either the cognitive resources of more than one individual or the collection of data that is especially hard to come by.

However, Kitcher in fact argues that we have reasons to reject ECI which go beyond the fact that scientific progress needs collective evidence gathering. He argues that scientific progress is dependent on the existence of institutions which fine tune the sorts of reward structures that are required to motivate scientists to research productively. On Kitcher's view, the success of science depends on the efficient working of invisible hand mechanisms. Scientists are typically not motivated by a simple and disinterested desire to find the truth. They may be moved by self-interested concerns, such as the desire for prestige, self-advancement, and power. Nevertheless, provided the social institutions of science have the right sort of reward structure, the overall goal of finding truth will be served. On this view, what distinguishes science from other forms of cognitive activity, and explains its success in arriving at approximately true theories, is that it involves social institutions which have the right sort of reward structure, a reward structure which is finely-tuned to producing the kinds of results which we value in science. ${ }^{53,54}$

While it is clearly true that children's theorizing, like that of adult scientists, takes place in a social setting there is no obvious reason, absent further argument, to think that the social settings in which children's theorizing takes place provide them with an analogous motivational structure. There are at least two reasons for thinking that it does not. First, child-rearing practices seem to vary enormously from culture to culture. It would be surprising, to say the least, if all of these different practices gave rise to the same finely tuned reward structure, let alone the same finely-tuned reward structure as that of a practice as culturally specific as contemporary Western science. Secondly, as Brad Wray has pointed out, we have good reason to think that insofar as the institutions of contemporary Western science are fine-tuned to produce motivational structures which do contribute to the success of science, we have good reason to think that they do so because they have been consciously designed to do so. ${ }^{55}$ There is no reason to think of child rearing-practices as having been shaped by conscious design in this way. ${ }^{56}$

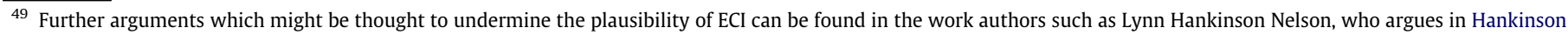

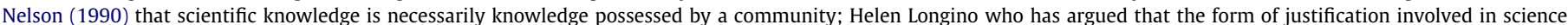

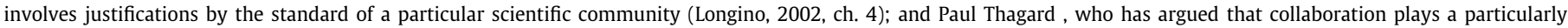

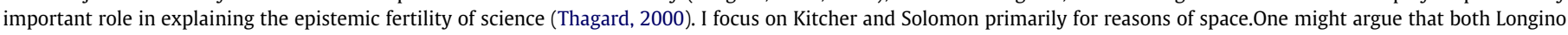

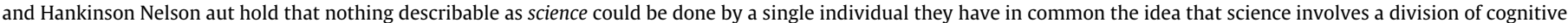

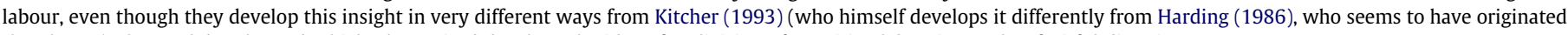
the phrase.) The work by Thagard which I have cited develops the idea of a 'division of cognitive labor' in another fruitful direction.

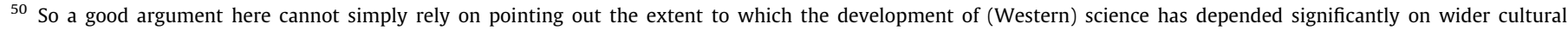

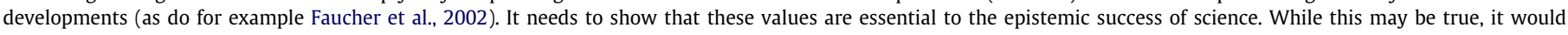

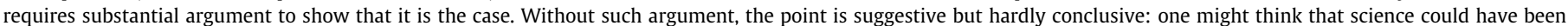
equally successful in some other cultural matrix than the one it actually developed in.

51 Note that if such arguments could be given, they would strengthen, rather than weaken my attack on ECI.

52 Gopnik \& Meltzoff (1997, pp. 24-26).

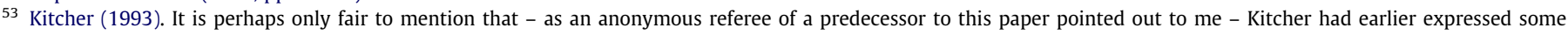

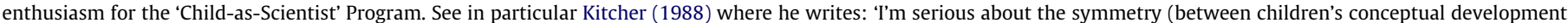

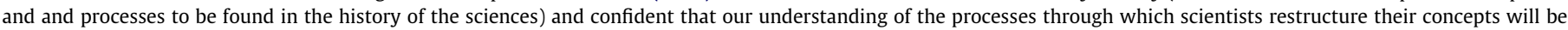
advanced by research on how they (or their con-specifics modified their childhood concepts.'

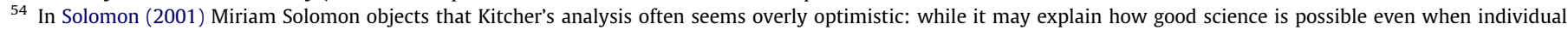

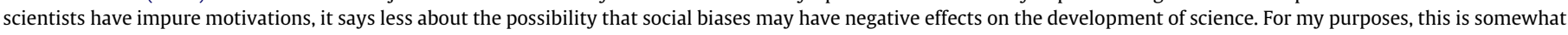

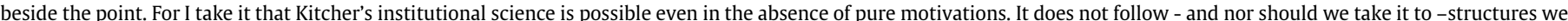

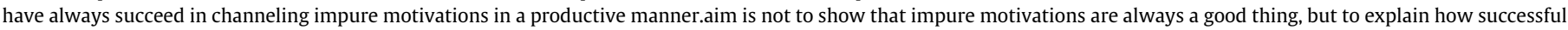

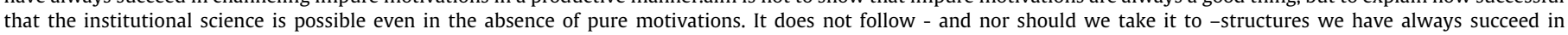
channeling impure motivations in a productive manner.

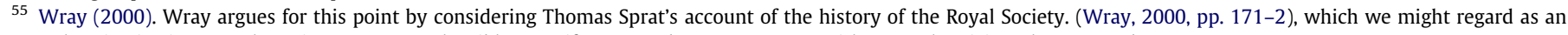
exemplary institution. But the point may seem plausible even if we regard Sprat's account with more skepticism than Wray does.

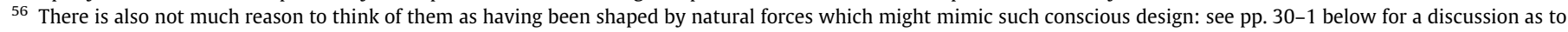
why we should not expect natural selection to select for optimal belief producing strategies.
} 
One might object that these are simply armchair considerations, and that what the argument requires here is empirical evidence about the ways in which institutions shape the motivations of children on the one hand, and mature scientists on the other. However this response does not help GM much. For it concedes that a defense of a plausible version of the Child as Scientist program will require empirical study of the role which the social setting of children plays in enabling their normal cognitive development. GM do not engage in any empirical study of this sort and it is not clear that their version of the Child as Scientist Program leaves them any room to do so. (GM do hold that the social setting of children may be relevant to their cognitive development. However, their view of how it might do so is extremely limited: the only possibility they consider is that social interactions provide children with more data to theorize about. ${ }^{57}$ If the arguments of this paragraph are correct this is not the only possibility they need to consider in order to make their case. ${ }^{58}$ )

A defender of the Child of Scientist program might argue that although Kitcher's analysis of the workings of science shows that social factors will play a role in explaining the success of science in situations in which a division of cognitive labour is required, scientific enquiry does not always require a division of labour of this sort. If so, and if the sorts of situation in which children are in are ones which do not require a division of labour of this sort then the factors which Kitcher considers can be disregarded.

GM suggest that the reason that science typically involves a division of epistemic labour is that the problems faced by mature scientists are difficult and typically require co-operative evidence gathering. An alternative view, which seems to underpin Kitcher's work, is that the successful prosecution of scientific enquiry involves the investigation of competing hypotheses by competing groups. ${ }^{59}$ If correct, a view like Kitcher's would explain the extent to which the institutions of science often seem to function in such a way as to promote competition as well as co-operation; while on GM's account, this would be at best a merely incidental matter, and at worst somewhat surprising. ${ }^{60}$

A defender of the Child as Scientist program might suggest in response that adults and children do not need to be motivated in the same kinds of ways in order to engage in the sorts of cognitive processes which lead to successful science. Indeed, one possible explanation of the extent to which impure motivations play a role in explaining the success of science is that these impure motivations are needed in order to restore to mature scientists the sort of intense impulse to engage in theory-construction which is natural (and perhaps even explicable in evolutionary psychological terms) in young children. On this view, the institutions of contemporary science would be to enable the motivation of competition against other scientists to substitute for a kind of innately supplied 'competition against nature' in the child. ${ }^{61,62}$

This response involves conceiving of the Child as Scientist program along lines which see an analogy between the ways in which children and individual scientists develop theories, rather than an analogy between children's development and the development of science as a whole. ${ }^{63}$ The underlying idea is that any kind of explanation of the success of science will have to appeal to the engagement of the right kind of cognitive mechanisms, and that these mechanisms might be engaged differently in adults and children. However, this begs the question against critics of ECI. For their view is that some of the key mechanisms that we should appeal to in explaining the success of science work on an intrapersonal rather than an interpersonal level. ${ }^{64}$

\subsection{Problems with ECI (2): Miriam Solomon}

These points suggest that Kitcher's work presents a major problem to the Child as Scientist Program. However, Kitcher's account of the role of institutions in science has been challenged by Stephen Downes who argues that Kitcher's account wavers between what he calls a 'thick' view of agency for the purposes of describing the phenomena which it sets out to explain, and a 'thin' view for the purposes of explaining those same data. ${ }^{65} \mathrm{By}$ a 'thin' view of agency, Downes means the sort of view of agency which is prevalent in neo-classical economics - in other words, one which views of agency as involving the rational maximization of some unitary good; while by a 'thick' view he means one which takes into account the ways in which human beings can be experimentally demonstrated to fall short of full rationality, and the empirical differences that exist between different forms of motivation.

Arguably, Kitcher's use of a thin view of agency simply involves a resort to a standard scientific strategy - that of constructing an idealizing model for explanatory purposes. However, within the particular dialectical context of a debate with GM about the merits and defects of ECI, Downes' point seems particularly significant. For it seems reasonable for researchers whose main concern is with giving a psychologically realistic picture of the sorts of human cognitive capacities that underlie our capacity for engaging in successful science to discount criticisms of their position which are based on a model of science which incorporates a psychologically unrealistic account of agency. Miriam Solomon has put forward a view which offers a way out of this impasse by offering a line of

\footnotetext{
57 Gopnik \& Meltzoff, 1997, p. 209 See Section 7 below for further discussion.

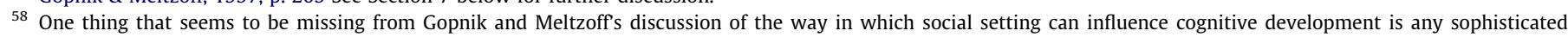

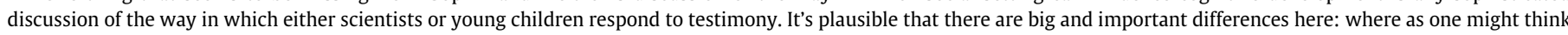

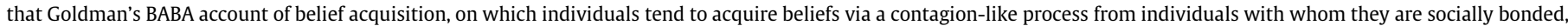

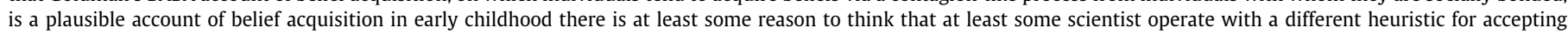
beliefs. (Goldman, 2004) (I would like to thank an anonymous reader for drawing my attention to the relevance of Goldman's work to the issues discussed here).

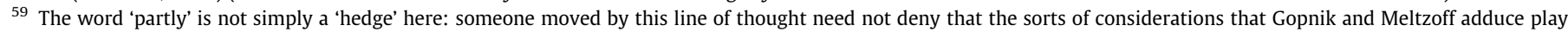

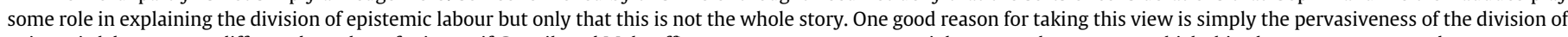

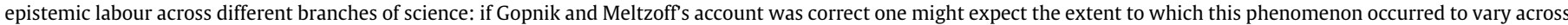
a spectrum from area to area, depending on the subject matter.

60 See for example Strevens (2003) on the role of the norm of priority in scientific publication.

61 I owe this way of seeing things to conversation with Josh Cowley.

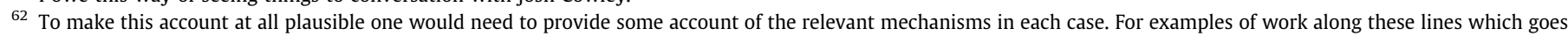

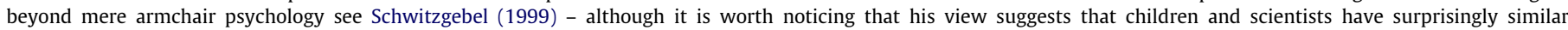
motivational structures.

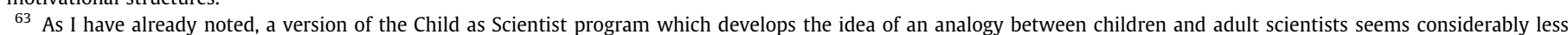
philosophically interesting than one that looks for analogies between children and science as a whole. I ignore this point here.

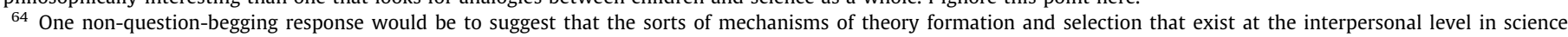

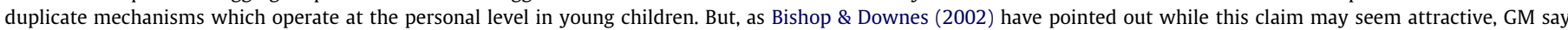

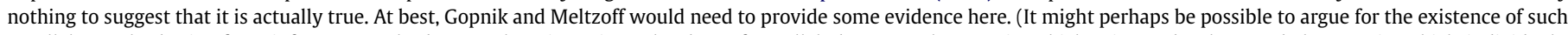

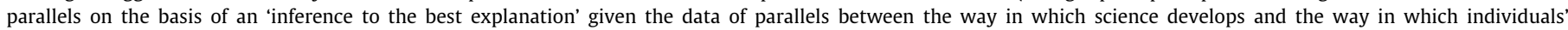
understanding of various domains develop. However, it's not clear to me how robust the data for which this is supposedly the best explanation actually is.)

65 Downes (2001).
} 
argument against ECI which engages with the psychological literature about agency and cognition in a more nuanced way. ${ }^{66}$

One aspect of Solomon's 2001 position sets her apart from Kitcher, and from her earlier work and has an important bearing on the implications of her view for the Child as Scientist Program. Solomon 2001 argues that a plausible account of the role which social institutions play in explaining the success of science should not start from the assumption that successful science necessarily involves a global community of scientists coming to a consensus on one particular theory in a given area. Instead, she suggests, science is successful when the distribution of belief within the scientific community matches the distribution of evidence. Since in many situations competing pieces of evidence point in different directions, an epistemically ideal science community will often be one in which there is no consensus.

This definition of a successful epistemic community is controversial. If we accept it then it appears to raise problems for the Child as Scientist program, at least if that Program is understood in the way I have been suggesting that it should be. For on this account there seems to be an important mismatch between the target of a theory of rational belief change in science and the target of the sort of explanation that an advocate of the Child as Scientist program wants to put forward. Within developmental psychology of the sort that GM are doing what is to be explained is how children settle on one particular theory of a target domain, and not how either individual children or groups of children distribute belief between different candidate theories.

I shall not explore this line of thought in detail for two reasons. First one might hold that in at least some cases the appropriate distribution of evidence across a community of scientists would involve that community coming to form a consensus, and one might look for analogies between these cases and cases of children fixing on a single theory in a particular area. Secondly Solomon's work provides us with reasons for being skeptical of ECI which are independent of these concerns about the rationality of consensus in a particular area.

One such line of thought relies on the idea that both motivational biases and what she calls 'cognitive biases' - features such as belief perseverance and salience effects, will very often lead individuals to accept theories which are less well-supported than their rivals, but that under the right sorts of circumstances these sorts of bias can counteract one another. Whether this happens in any particular case will depend on the form which the social institutions of science take ${ }^{67}$ However, insofar as the social institutions of science interact with cognitive biases in such a way as to ensure that the distribution of belief within a society matches the distribution that would be given if only epistemic factors played a role, they are relevant to explaining the success of science. In the perhaps rare case where consensus is appropriate, it seems as though this would require social biases and epistemic biases to cancel one another out. ${ }^{68}$ And to the extent that cognitive biases are ineliminable, it seems to follow that social factors would be involved in explaining the epistemic success of science. In other words ECI turns put to be false.

Solomon's arguments present the advocate of the Child as Scientist problem with a dilemma. Either children are subject to the same kinds of cognitive biases as adults or they are not. If not, this suggests that children are in an epistemically superior position to mature scientists, and seems to undermine the case for thinking that a comparison between children and scientists will be illuminating. On the other hand, if, as seems more plausible, they are subject to these biases, then the Child as Scientist Program seems importantly incomplete: it owes us an account of the sorts of countervailing mechanisms which, in the child's case, do the work which is done, on Solomon's account, by the social institutions of science.

One somewhat speculative response to this argument may be worth considering. It is that while the sort of biasing factors to which Solomon draws attention need to be compensated for in grown-up science, they do not threaten children's construction of common-sense theories in the same way. Indeed, they might even, on occasion play a positive role in children's learning. Perhaps evolution has provided us with a set of cognitive biases that made us more, rather than less, likely to come up with true common-sense theories in the sorts of areas that children needed to theorize about.

This response has two weaknesses. First, we should not always expect evolution to set us up to acquire true theories. For there might be cases in which biases towards falsehood in certain areas might be more fitness enhancing (for example, if errors of one sort are much more costly than errors of another sort, then we might expect evolution to 'overcompensate' by giving us a cognitive system which was much less likely to produce the second sort of error even at the expense of giving us more errors of the first sort and even more errors overall) ${ }^{69}$. Second, it is hard to see how there could be a set of more or less 'topic-neutral' cognitive biases which impacted positively on the sorts of theorizing that children needed to engage in while impacting negatively on the sorts of theorizing that adults were engaged in. ${ }^{70}$

\section{Concluding Remarks}

I have argued that there is a tension between GM's advocacy of a picture of science which is committed to a form of cognitive individualism, and their claim that it is analytic philosophers of science who are best placed to tell us about what science is. ${ }^{71}$

One response would be to suggest that the turn away from cognitive individualism in recent philosophy of science is a mistake. This seems unlikely: Epistemic Cognitive Individualism is a doctrine which should ought to seem implausible once it is explicitly formulated. To an unprejudiced eye, two features of science seem to stand out. The first is the complexity of the division of epistemic labour which science involves. The second is the degree to which science, more than any other field of cognitive endeavour, seems

\footnotetext{
66 Solomon $(1994,2001)$.

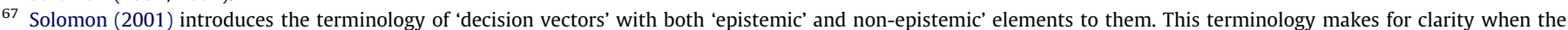

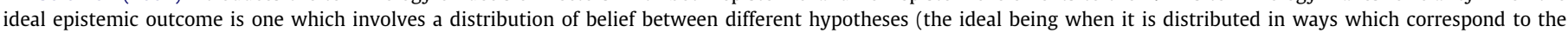

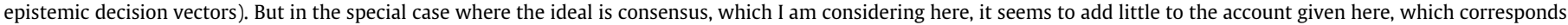
to that found in Solomon (1994).

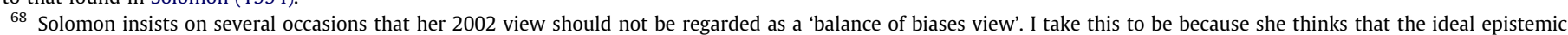

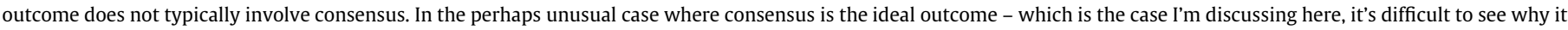
would not be appropriate to see here position in the way I have suggested.

69 Stich (1990) and Sterelny (2003).

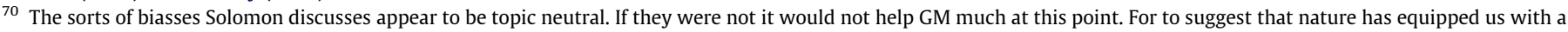

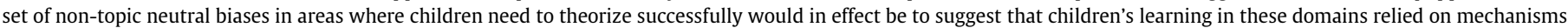
which were not the same as the mechanisms which underpinned successful scientific theorizing.

71 As evidenced by their reliance on the literature from analytic philosophy of science in giving an account of what a theory is: see Gopnik \& Meltzoff, pp. $32-41$.
} 
to be clearly progressive. There seems to be a good prima facie case for thinking that these two are significantly linked. ${ }^{72}$

A better response would be to attempt to reformulate the Child as Scientist Program in a way as to avoid any commitment to Epistemic Cognitive Individualism. There is no obvious reason why this should be impossible. I have argued that the Child as Scientist Program is best understood as a view about analogies between conceptual development in science and in young children. Someone who accepts this needs not thereby be committed to any particular view about the nature of science.

Would this entail a drastic a revision of GM's position? Perhaps not. One might think that their position, as explicitly stated, is compatible with something like the following view: both scientists and young children are - like all cognizers ${ }^{73}$ - embedded in social settings which play an important role in scaffolding their cognitive development, and these social settings play a similar role in scaffolding the development of science and in the cognitive development of children. ${ }^{74}$

Nevertheless, the Child as Scientist Program is not simply a set of written views, but a program of research in developmental psychology. As Lakatos and Kuhn have taught us, understanding a programs of research involves more than simply understanding views which are explicitly formulated. Programs of research can also include unformulated or half-formulated assumptions which influence the questions which researchers regard as worth taking seriously.

If one thinks that the interaction between social settings and the cognitive mechanisms of individual cognizers plays an important role in understanding cognitive development, then it seems plausible that these interactions will merit detailed empirical investigation. GM and researchers influenced by them have shown relatively little interest in investigating such matters. Furthermore even when they do concede that social setting does play a role in cognitive development, they do so in a way which shows just how committed they are to ECI. For when they consider the role of social setting in cognitive development they tend treat children's relations with others as simply providing them with another sort of data to theorise about. ${ }^{75}$

A version of the Child as Scientist program that did not incorporate ECI could, then, be expected to be different from what GM have given us in two respects. First, we might expect it to emphasise the interaction between the cognitive and the social to a greater extent and to make it more explicitly the object of detailed empirical study. Secondly, we might expect it to conceptualise these interactions as involving more than the acquisition of new kinds of data by enquiring subjects. One might nonetheless hope that it could be intellectually fruitful, and also that it might attract the interest of philosophers of science whose sympathy with some aspects of the Child as Scientist Program is in tension with their rejection of cognitive individualism. ${ }^{76}$

\section{Acknowledgments}

I would like to thank Radu Bogdan, Josh Cowley, Mark Ashton Smith, participants in a work in progress seminar in the centre for Mind, Culture and Society at Bilkent University, and an audience at the annual conference of the British Society for the
Philosophy of Science, along with a number of readers who I am not in a position to name for helpful comments on earlier drafts.

\section{References}

Bishop, M., \& Downes, S. (2002). The theory thrice over: The child as scientist, superscientist or social institution? Studies in History and Philosophy of Science, 33(1), 117-132.

Downes, S. (1993). Socializing naturalized philosophy of science. Philosophy of Science, 60(3), 452-469.

Downes, S. (1999). Ontogeny, phylogeny and scientific development. In V. Hardcastle (Ed.), Where biology meets psychology: Philosophical essays (pp. 273-285). Cambridge: MIT Press.

Downes, S. (2001). Agents and norms in the new economics of science. Philosophy of the Social Sciences, 31(2), 224-238.

Faucher, L., Mallon, R., Nazer, D., Nicholls, S., Ruby, A., Stich, S., et al. (2002). The baby in the lab-coat: Why child development is not an adequate model for understanding the development of science. In P. Carruthers, S. Stich, \& M. Siegal (Eds.), The cognitive basis of science. Cambridge UK: Cambridge University Press.

Gauvain, M. (1998). Cognitive development in social and cultural context. Current Directions in Psychological Science, 7, 188-192.

Gauvain, M. (2001). Cultural tools, social interactions, and the development of thinking. Human Development, 44, 126-143.

Giere, R. (1988). Explaining science-A cognitive approach. Chicago IL: Chicago University Press.

Giere, R. (2002). Scientific cognition as distributed cognition. In P. Carruthers, S. Stich, \& M. Siegal (Eds.), The cognitive basis of science. Cambridge UK: Cambridge University Press.

Glennan, S. (2005). The modeller in the crib. Philosophical Explorations, 8, 217-228.

Goldman, A. (1999). Knowledge in a social world. Oxford: Clarendon Press.

Goldman, A. (2004). Pathways to knowledge. Oxford: Oxfod University Press.

Gopnik, A. (1996). The scientist as child. Philosophy of Science, 63, 485-514.

Gopnik, A. (1998). Explanation as orgasm. Minds and Machines, 8, 101-118.

Gopnik, A. (2003). The theory as an alternative to the innateness hypothesis. In L Antony \& N. Hornste (Eds.), Chomsky and his critics. Oxford: Blackwells.

Gopnik, A., \& Meltzoff, A. (1997). Words thoughts and theories. Cambridge MA: MIT Press.

Gopnik, A., \& Meltzoff, A. (1998). Theories vs. modules: To the max and beyond a reply to Poulin-Dubois and to Stich and Nichols. Mind and Language, 13, 3.

Gopnik, A., Meltzoff, A., \& Kuhl, P. (1999). The scientist in the crib: Minds, brains and how children learn. New York: William Morrow.

Gopnik, A., \& Schulz, L. (2004). Mechanisms of theory formation in young children. Trends in Cognitive Sciences, 8, 371-377.

Gopnik, A., \& Schulz, L. (Eds.). (2007). Causal learning: Psychology, philosophy, and computation. New York: Oxford University Press.

Gopnik, A., \& Tenenbaum, J. (2007). Bayesian networks, Bayesian learning and cognitive development. Developmental Science, 10, 281-287.

Hankinson Nelson, L. (1990). Who knows: From quine to a feminist empiricism. Philadelphia: Temple University Press.

Harding, S. (1986). The science question in feminism. Ithaca and London: Cornell University Press.

Hull, D. (1988). Science as a process: An evolutionary account of the social and conceptual development of science. Chicago: University of Chicago Press.

Hutchins, E. (1995). Cognition in the wild. Cambridge MA: Bradford Books MIT Press

Kitcher, P. (1988). The child as parent of the scientist. Mind and Language, 3. 217-228.

Kitcher, P. (1993). The advancement of science: Science without legend, objectivity without illusions. Oxford, UK: Oxford University Press.

Knorr-Cetina, K. (1999). Epistemic cultures: How the sciences make knowledge. Cambridge, MA: Harvard University Press.

Logino, H. (2002). The Fate of Knowledge Princeton. Princeton University Press.

Murphy, D. (2006). On Fodor's analogy: Why psychology is like philosophy of science after all. Mind and Language, 21, 553-564.

Rogoff, B., \& Toma, C. (1997). Shared thinking: Community and institutional variations. Discourse Processes, 23, 471-497.

Schwitzgebel, E. (1999). Children's theories and the drive to explain. Science \& Education, 8(1999), 457-488.

Solomon, M. (1994). Social empiricism. Nous, 28, 323-343.

Solomon, M. (1996). Commentary on Alison Gopnik's 'The Scientist As Child. Philosophy of Science, 63, 4.

Solomon, M. (2001). Social empiricism. Cambridge MA: MIT Press.

Staley, K. (2005). The evidence for the top quark. Cambridge, UK: Cambridge University Press.

Sterelny, K. (2003). Thought in a hostile world. Malden, MA: Blackwell.

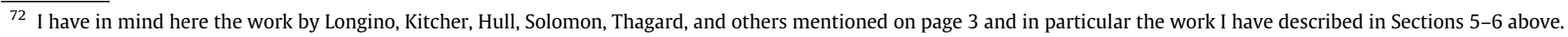

73 As Murphy (2006) emphasises.

74 I am grateful to an anonymous reader for this point.

75 Gopnik \& Meltzoff (1997, p. 209).

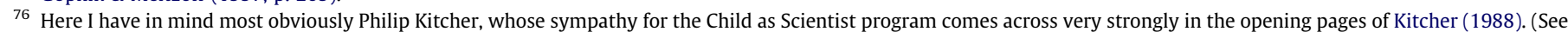

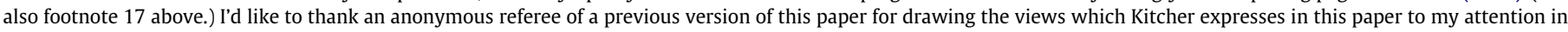
this context.
} 
Stich, S. (1990). The fragmentation of reason preface to a pragmatic theory of cognitive evaluation. Cambridge, MA: MIT Press.

Stich, S., \& Nicholls, S. (1998). Theory to the Max. Mind and Language, 13, 421-449. Strevens, M. (2003). The role of the priority rule in science. Journal of Philosophy, $100,55-79$.
Thagard, P. (2000). How scientists explain disease. Princeton University Press. van Fraassen, B. (1980). The scientific image. Oxford UK: Clarendon Press.

van Fraassen, B. (2002). The empirical stance. New Haven, CT: Yale University Press. Wray, K. B. (2000). Invisible hands and the success of science. Philosophy of Science, 67, 163-175. 